\title{
BIM AND CASTELLO SFORZESCO IN MILAN. A PARTICULAR APPROACH TO DIGITIZATION OF THE ARCHITECTURAL AND INFORMATION HERITAGE.
}

\author{
F. Guzzetti ${ }^{1}$, K.L.N. Anyabolu ${ }^{1}$, F. Biolo ${ }^{1}$, R. Dell'Orto ${ }^{1 *}$ \\ ${ }^{1}$ Politecnico di Milano, Department of Architecture, Built Environment and Construction Engineering, 20133 Milan, Italy - \\ (franco.guzzetti, karenlara.anyabolu, francesca.biolo, riccardo.dellorto)@ polimi.it
}

Commission V, WG V/7

KEY WORDS: Digital twin, information heritage, Castello Sforzesco, methodological approach, BIM, digitization.

\begin{abstract}
:
In the architectural and construction field, the BIM methodology is becoming increasingly predominant and it has become widespread in recent years thanks to the advantages provided in the framework of project management and interoperability. These digitization processes have led to efficient standards for new construction interventions. On the contrary, more applications have shown how this process is far from univocal and linear for Architectural Cultural Heritage. These difficulties derive from the complexity of the constructions but also, and above all, from managing the information heritage connected to the digitized object. The work presented in this paper aims to define a general operating model, widely applicable, for the digitization of the information asset related to the architectural heritage, exploiting the digital model of the object. This theme has been declined concerning a particular case study, with monumental characteristics and value: the Castello Sforzesco in Milan. This research work starts from the information connected to this particular building, a countless and often extremely articulated heritage, due to its stratification over time. To better manage this complex aspect, an approach has been developed that starts from a 3D digital model of the Cultural Heritage $(\mathrm{CH})$, associated to different levels concerning as many information packages (history, documentation, facility management, tourist fruition, etc).
\end{abstract}

\section{INTRODUCTION}

Today's world is facing an increasingly technological presence that led processes, objects and services to change shape, taking on a digital character. In this context, the architecture sector has seen a growing interest in digitization. Multiple research and trial have started in this area, developing different but parallel themes within the world of digital twins: survey, 3D modelling, facility management, information fruition, etc (Battini and Landi, 2015; Osello et al., 2018).

BIM (Building Information Modeling) workflows intercept several of these themes and are now part of a common scenario in this sector. The introduction of this tool represents an international reform and its presence is already deeply rooted in new buildings. Although in the various Countries the deadline for the mandatory use of BIM for existing buildings management is increasingly stringent, for example in Italy it is 2025 (Ministry of Infrastructure and Transport, Ministerial Decree, 1-12-2017, n. 560), it is still difficult to think of a standardized HBIM (Heritage Building Information Modeling) approach. In the current context, where soil consumption is an increasingly delicate issue, the necessity to better manage preexisting buildings (Guzzetti et al., 2021) becomes even more evident, while also handing down their knowledge and rich heritage.

This digitization process has a higher level of complexity in an existing building than in a new one due to different factors as the irregularity of geometries and the lack of software commands (Guzzetti et al., 2018). However, the main challenge is the management of the huge information assets connected to these structures. A further difficulty is to maintain, in the digital copy, the building's interpretation of the history: the description of the transformations, the phenomena that have affected it, the historical archives and the sources that deal with it. These indications, sometimes particularly linked to the specific case study, are difficult to standardize and can be inserted within a single BIM model. For this reason, the construction of an effective and unique digital object to which all its information is associated, including historical and documentary one, is a complex operation. The management and use of information once again cross the world of modern ICTs and their potentiality in the communication field.

The work presented here starts from these premises and it is part of a wider work, still in progress. The goal is to obtain a method, applicable to any other architectural heritage, capable of structuring a single information tool, designed to improve management operations and encourage its knowledge, exploiting the digital model of the object.

To develop the work, the case study used was the Castello Sforzesco in Milan, an iconic building of the Lombard city, characterized by an articulated architecture and an intricate history. Indeed, it is a characterizing monument of its territory, whose tale has its roots in the XIV century and its events concern both the city of Milan and multiple foreign dominations. Its rich history, articulated architectural changes and multifaceted character (war structure, stately home and artistic receptacle) give this $\mathrm{CH}$ a remarkable complexity, especially in terms of information and knowledge. This aspect has made it possible to test the hypothesized approach, verifying its effectiveness even for particularly complex and difficultly standardizing cases. Indeed, the aim is to define an 


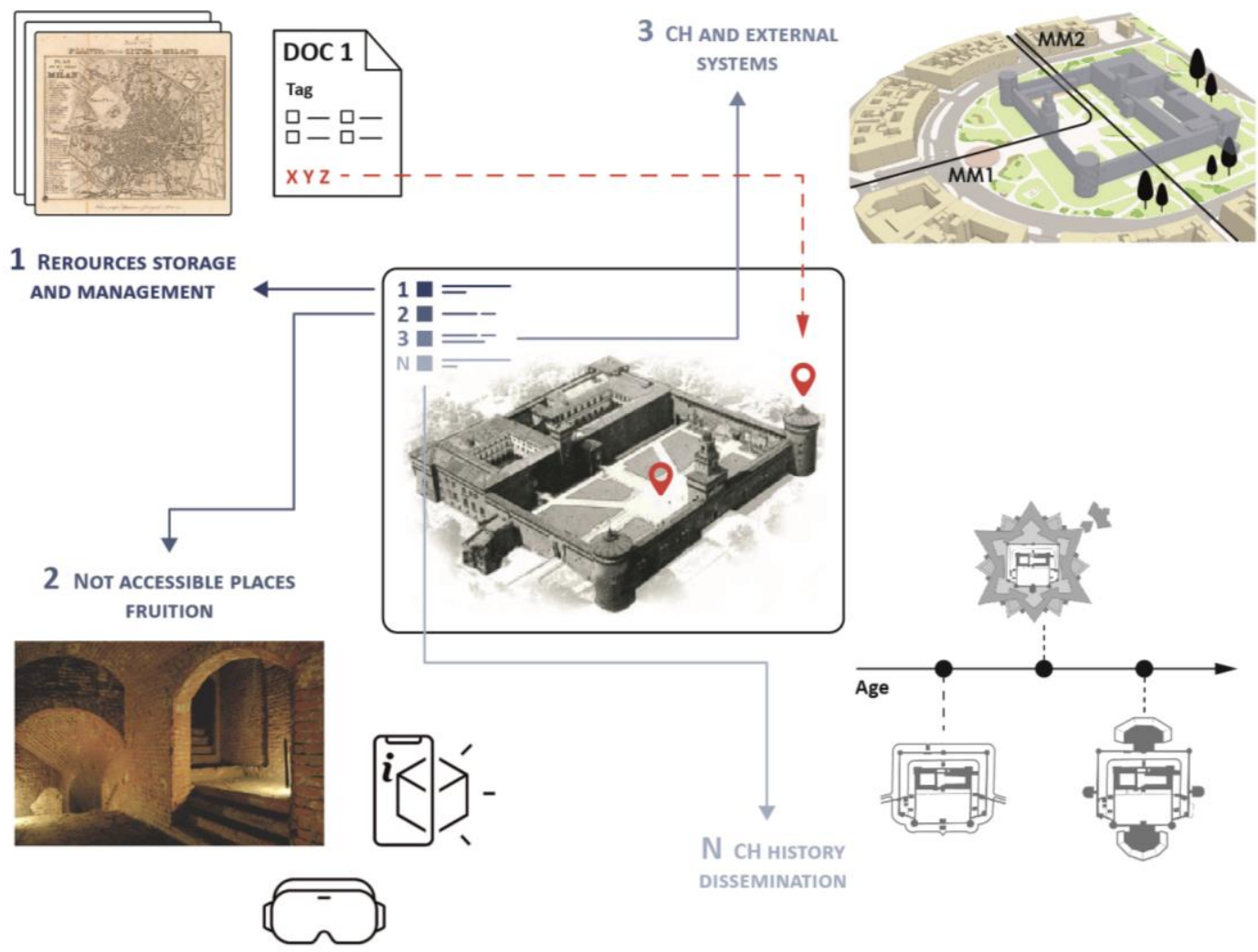

Figure 1. Logic scheme of the BIM model

easily replicable model for other $\mathrm{CH}$, able to handle the inheritance and complexity of these assets.

\section{THE DIGITAL COPY OF THE CASTELLO SFORZESCO}

The work carried out represents an answer to a growing need in the architectural field: to transfer the management, conservation and dissemination of cultural heritage to a digital environment. It is a matter of providing a flexible solution that respects the features of the individual case, adapting to them without changing its framework and standards.

The research has led to a compound and heterogeneous digitalization model, to respond effectively to the multiple necessities of this kind of buildings, which do not adapt to current BIM standards, designed for new construction interventions.

\subsection{The logic scheme of the BIM model}

At the centre of this development, we have chosen to place the $\mathrm{CH}$, in our case the Castello Sforzesco. The idea is to provide an operating model able of telling the user the history of architecture and, at the same time, of managing its information heritage. Indeed, the founding idea of BIM is to associate information with the building and/or the elements that compose it. To read the information related to the object itself, a model of the $\mathrm{CH}$ must remain the fulcrum of the system.

The proposed digitization approach is made explicit by Figure 1. The general digital object, with its geometric information, remains at the centre. It is a $3 \mathrm{D}$ digital model of the building inserted in a BIM-GIS system and completed by a series of information layers, independent in the level of detail (LOD). The latter regards the various aspects of the building and its relationship with the context: characteristics of the construction elements, facilities, specifics of maintenance interventions, etc. These are all data you would expect to find in a BIM model. In addition, always in the digital copy, it is necessary to transmit this information by loading them with the historical factor. The future choices, design, management and use of the building, must always pass through the interpretation of the events of the past. In the end, with regard to the digitization of $\mathrm{CH}$, other information must be considered and systematized: the historical events that have intercepted the building, the architectural evolution over time and much more.

These different information layers, connected to the central model, are treated following the needs of the same information to be digitized. Indeed, the various types of data may require different methods, tools and processing techniques. All this leads to the development of multiple approaches to digitization but collected within a system that coordinates them, evolving the idea of the single and unique model. The experience still in progress describes the possible methods to manage the wide informative heritage of historical architecture (Stanga et al., 2017; Tommasi et al., 2019). It will be fundamental to research within the opportunities offered by digital technologies for the recording (laser scanner and photogrammetry) and digitization (modeling software) activities and by new ICT.

The goal is to create new virtual places of knowledge composed by a digital twin of the building able to organize all the information related to it. This latter regards also bibliographic documents and cartographic/iconographic material, relationship with the surrounding elements, historical description, and 
material prepared for tourist dissemination, etc. A single digital place of knowledge and fruition of the building. This central digital twin, correct in geometry and characteristics, can become library of its own information, providing a new and agile way of making use of it. The goal is to obtain a method, applicable to any other architectural heritage, capable of structuring a single information object, designed to improve management operations and encourage its knowledge.

\section{THE LEVELS OF INFORMATION}

The information is organized in several packages, which are connected to the central reference 3D model. All this allows the localization of the information itself and their reading on the object to which they refer (the building or part of it). Therefore, the information asset is structured in these packages, within which homogeneous data are arranged. Since the various levels collect information of a different nature, the organization and management of it take place differently. This approach, therefore, adapts to the theme covered: description of architectural evolution, facilities management, collection and organization of archive material, etc.

In this way, it is possible to collect much more information in the same space, while at the same time denying the idea of the unique model and using many different autonomous but aggregated spaces/levels. From this methodological approach, insights have been developed. They are some of the levels constituting the digital twin, declined within the case study of the Castello Sforzesco in Milan.

\subsection{Tagging historical documentation}

The first insight deals with documents' storage and management (Biagetti, 2019). Architectural heritage is often associated with a wide number of bibliographic, iconographic and cartographic resources that contain relevant information on their history and development. These data constitute invaluable knowledge and fundamental information for understanding architectural structures and preparing appropriate interventions for the building. This documentation is part of the information asset related to the $\mathrm{CH}$ and is not only the subject of study for architectural historians.

Information is often in several archives, libraries and offices, and it is sometimes difficult to access. These logistical difficulties affect the possibility of knowing and understanding the structures and of handing them down over time. The idea of document archiving must be somehow revolutionized (Brienza and Fornaciari, 2020), thus finding a more effective way to enhance and tell the tale of architectural heritage like our case study.

The solution, here exposed, consists of an information level dedicated to archival material, agile in use and easily expandable. The system uses multiple tags to create multiple typological and thematic categories. As we will see below, this approach allows both a vertical search, among typologically similar documents, and a horizontal one, basing the operation on the content of resources (Figure 2). Thanks to these tags, each digital record is equipped with multiple attributes. Latter act both as an organizational principle for the documents, during the storage phase, and as a research tool.

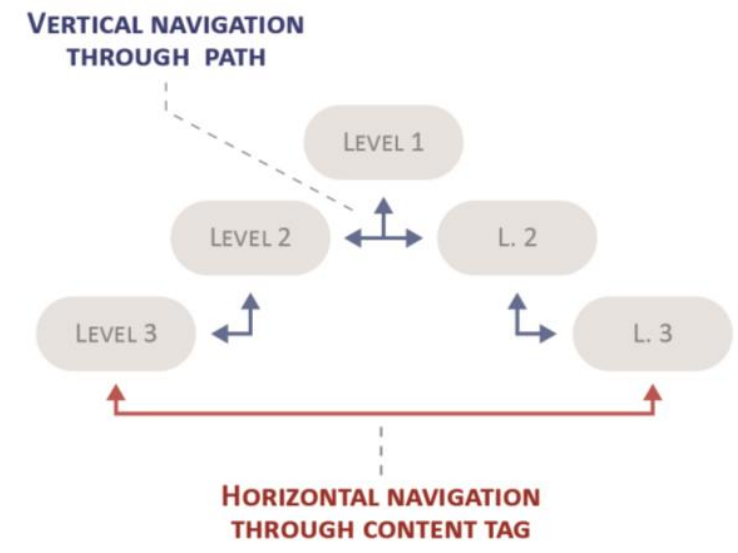

Figure 2. Vertical and horizontal navigation within the system

This system was checked on the case study and its extensive documentation. This experimentation has led to the definition of three + one levels of tagging (Figure 3 ), of which a practical example is also given (Figure 4):

1_Category tags. This label allows the division of the material according to their nature: text documents or graphic works. This first subdivision gives the possibility to view documents through two main vertical paths, which reflect the nature of the documents. Unlike the type tags below, the category tag for each record is only one, to define uniquely the two principal paths of research. It is possible to find graphics with short texts and it is natural to read illustrated books but all this does not affect the predominant nature of a document.

2_Typology tags. The second level concerns the definition of the type of document. In the case of text documents, for example, tags are used to divide them into books, articles, correspondence material, documents describing interventions, etc. The same applies to graphic designs. For this second step, it is possible to use multiple labels. Indeed, verifying the operating model with the documentation of the Castello Sforzesco, it was immediate to understand that some documents do not have a univocal and clear typology. For example, it is common to trace cartographic material accompanied by photographs, or other material with a heterogeneous character. This second level allows also to provide search filters, according to users' fruition.

3_Content tags. The third categorization level concerns the content of the documentation. Some keywords indicate the content covered in the document. Thanks to these tags it is possible to structure a horizontal search mode. This selection typology, unlike vertical paths, touches both categories of documents, suggesting to the user similar records based on the content. Therefore, these suggestions are focus on the congruence between tags. The amount of these labels may vary, but based on the experiments conducted, they cannot be too generic. In this case, the idea of the suggestion based on the specific theme would be missing in favour of a wider spectrum of selection. The description keys for the various documents can be dating, names of particular interest (architect, artist, client, etc), specific place and subject of the document. 


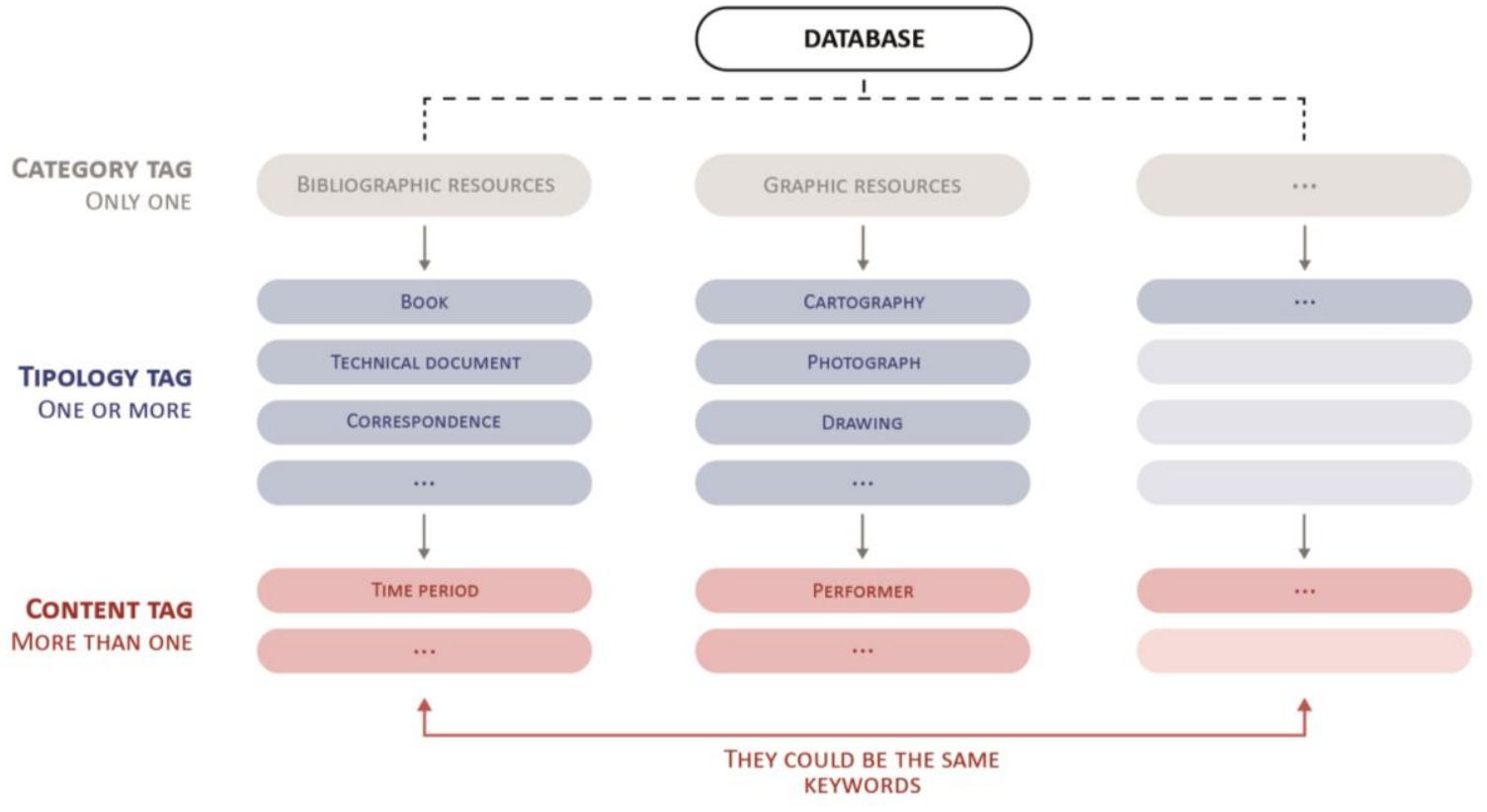

Figure 3. Representation of the tagging system

4_GeoTag. It is an attribute that does not regulate the categorization of documents but that allows them to be placed on the central model of the $\mathrm{CH}$, to display data on the object. This geolocation can be general and affect the whole building or only a part of it. In this second case, the GeoTag is preferably also reflected in content tags, which indicates the specific place.

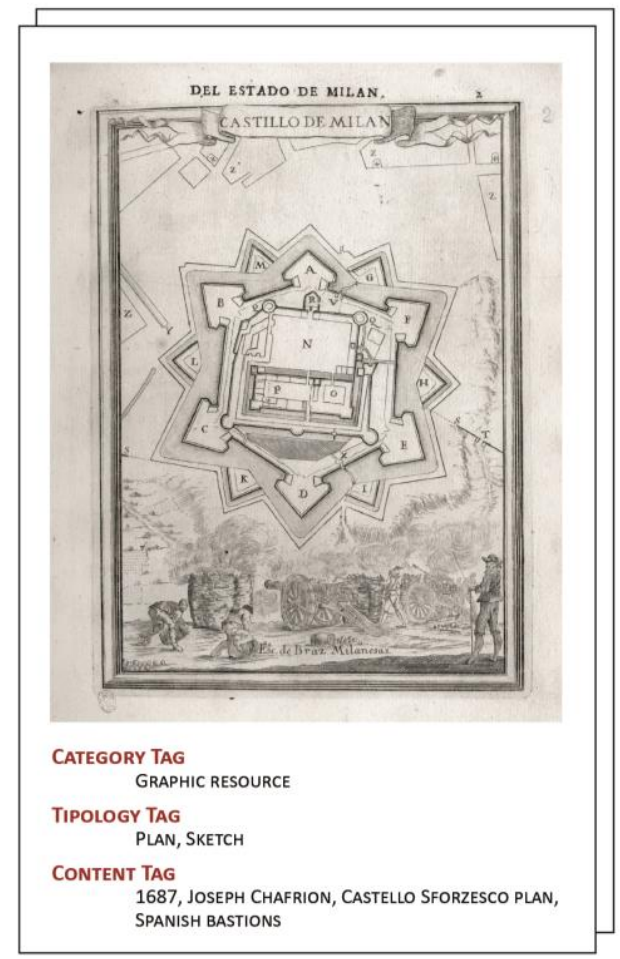

Figure 4. An example of documentation tagging

For documents insertion in the database, it is sufficient to attribute the various tags to the document itself, selecting those already used. This foresight allows avoiding that some tags are doubled unnecessarily, due to different semantic choices (e.g. Leonardo da Vinci and L. da Vinci). During the archiving phase, it is proper to give each record also a quotation, taken from a defined scale of values. This operation allows you to hierarchize the documents and assign them to multiple value bands, based on the amount of information contained in it. By assigning each document a rating, suggestions of the horizontal research will be selected not only on the content tags but also on their position within the rating system. The evaluation, although not entirely systematizable, allows the user to get the main material more easily. The present operating model allows a theoretical unlimited implementation of the database, easily feasible, generating over time a large container of information.

This proposal stems from the conviction that it is necessary to find a way to simultaneously enjoy the virtual $\mathrm{CH}$ and have all this accessible, as a single digital archive. By exploiting labels and geolocation, the work develops a cataloguing process that allows both to connect the documents to the central model and to exploit them in an agile and simple way from a single digital space.

\subsection{Relationship between $\mathrm{CH}$ and external systems}

This second paragraph describes the functionality of the system described above when it deals with the relationship between $\mathrm{CH}$ and external systems. Buildings due to their presence on the territory, interface with several factors. The latter can be more complex systems such as infrastructure or individual elements, such as other buildings. Relationships and solicitations can be temporary, periodic or permanent. Many of these external factors are important elements for understanding the building, especially when it shows degradation or structural phenomena. The architectures are part of a network of systems, in constant interaction. It is as well on this principle that the theme of smart cities (Angelidou et al., 2017; Gribaudo et al., 2017) is grafted. This process has been increasingly expanding in recent years, together with the world of IoT (Atta and Talamo, 2019; Lerario and Varesano, 2020). 
Within this multitude of relationships, architectural heritage is a delicate element that is extremely sensitive to changes that alter the equilibrium of these bonds. Precisely for this reason, information related to the systems and elements in close contact with them, must be included in the study of $\mathrm{CH}$.

For this section, the typical features of the GIS world and its software have proven to be an optimal solution. This is precisely because of the predisposition of the GIS approach to managing large and heterogeneous spaces, and not individual buildings, as for BIM. As well in this case the working model is declined in a separate information layer or more levels in the case of several systems in interaction. For the case study, a simple trial was carried out, analyzing the relationships between the Castello system and that of the surrounding greenery. Indeed, Parco Sempione is adjacent to the Milanese fortress, one of the green lungs of the city. This area, characterized by a rich arboreal apparatus, also develops near the fortress with trees of considerable size. As we shall see later, the Castle has an articulated underground infrastructure, which is a trace of the Ghirlanda. This structure overlooks the moat of the Castle, with 100 windows, but is entirely covered by the ground of the park. The goal is to verify how these two systems interact with each other and whether the root system of the trees can be a threat to the already fragile structure of the Ghiranda.

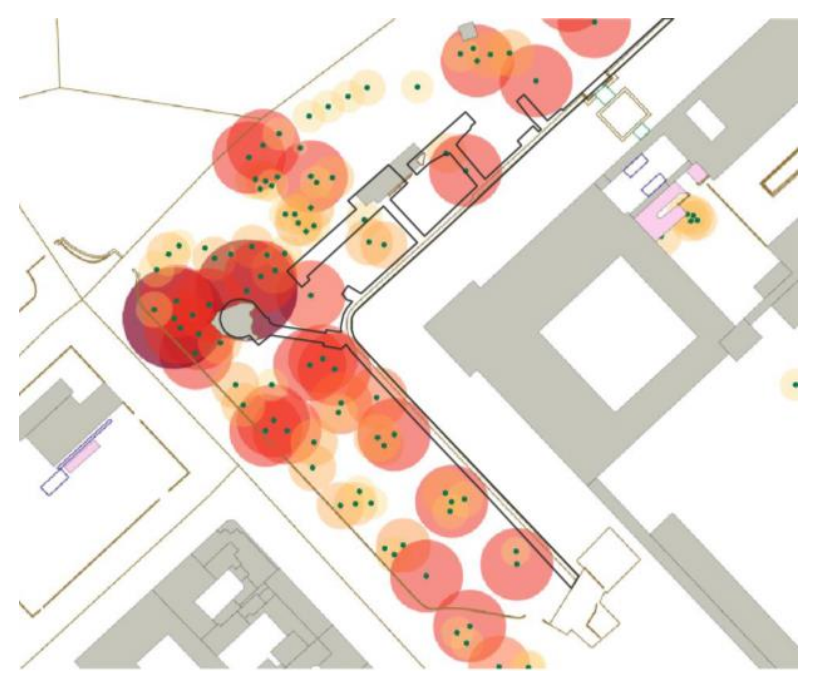

Figure 5. Relationship between the underground structure of the Ghirlanda and the trees system of the park

First of all, it was necessary to insert the information about the surrounding vegetation in the GIS environment. The material, in shapefile format, was downloaded from a website of the municipality of Milan, R3 Trees. This is the database of the green areas of the city. From the Parco Sempione file, only the elements near the Castle have been considered. The latter does not have, as an attribute, indications on the depth of the root system but there was information relating to the genre and species of plants. Considering that the depth of the roots is on average equal to half the radius of the foliage, it was sufficient to find this information. The operation was possible by consulting the CiTree website, a German database that provides data useful for the design and management of greenery. By importing a new Excel $\odot$ file into the GIS environment, with the missing information, it was possible to implement the attribute table of the original layer. A buffer has been set around the trees, based on the "depth of the roots" data. In this way, it was possible to identify the areas where there are the deepest roots (Figure 5). This indication allows defining the spaces and the construction elements to be kept under control and possibly to be subjected to some structural improvements.

This simple example presents some points to be enhanced (which will be deepened in the future), such as the 3D visualization of information. Having said that, it equally addresses the potential of the approach within an analysis of this type. In addition, based on the GIS work structure, it fits well with the previously mentioned approach to digitization.

\subsection{Spaces fruition}

A further part of the work deals with solutions for making digitally available inaccessible or non-visitable spaces. Physical inaccessibility to some structures, or part of them, is a common condition to many historical buildings and touches both the world of tourism and the practice of professional activities. For example, in museums, there are closed rooms for maintenance activities (Carrion-Ruiz et al., 2019). Sometimes, instead, it is not possible to access a building for security reasons (Moretti et al., 2016). The possibilities offered by today's survey and communication technologies offer effective solutions for the experience and knowledge of closed or only partially usable spaces.

This theme touches on other aspects, as the musealization of Architectural Heritage. The purpose of these initiatives is twofold: the dissemination and preservation of the building. The opportunities provided by new technologies increasingly act as catalysts for this enhancement process. The digitization of the $\mathrm{CH}$ crosses also the topic of the Virtual Museum (Partarakis et al., 2017; Bolognesi, 2018), a broader and more democratic way (Garnero and Minucciani, 2017) to disseminate the tangible and intangible heritage (Santagati et al., 2018). This transformation finds consensus and support from administrative and governmental agencies, with increasingly detailed guidelines (European Commission, 2020; Council of Europe, 2021, UNESCO, 2021; United Nation, 2021; MiBACT, 2021). These documents make explicit the importance of preserving existing architectures by exploiting cutting-edge technologies and new tools, like ICT.

This part of the work was dedicated to setting the way of use for digital objects, through today' ICT solution. This study was made on our case study, so on inaccessible spaces of the Castello Sforzesco, exploiting modern survey technologies like laser scanning and photogrammetry (Agnello et al., 2019, Dhanda et al., 2019). The idea is to link the digital survey of these spaces to the central model, as it is part of the information heritage.

A digital survey, of some portions of the Castello Sforzesco, was carried out using laser scanner technology (Faro CAM2). The operations involved part of the underground spaces of the Ghirlanda (Torre della Colubrina, a portion of the main path, Porta del Soccorso), a war structure dating back to the ViscontiSforza period (Padovan, 1996; Padovan 2019), composed of tunnels and punctual vertical developments (Figure 6). The survey included about sixty scans, linked to a georeferenced topographic network. The result was a set of 3D models of the spaces, in the form of point clouds. The choice of this digitization process derives from the relative ease in obtaining very faithful results in the geometries and from the effectiveness of these objects in the perception of spaces. Reiterating what was said above, these products are part of that information heritage of the $\mathrm{CH}$. Therefore, the intention is to prepare, in the central system, access to these digital spaces. 

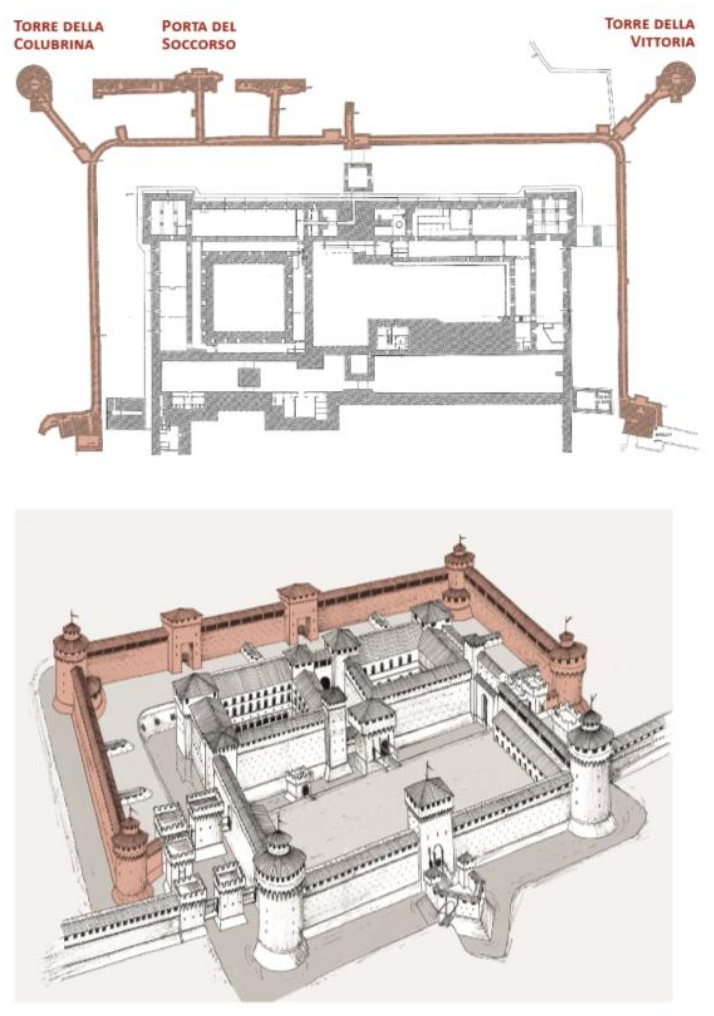

Figure 6. Plan of the Ghirlanda (top) and a reconstruction of its ancient shape (bottom)

The virtual tour of them, especially when it comes to using 3D models and not just $360^{\circ}$ photos (or similar), involves files of considerable size. The solution identified connects this material to the central model but allows to use of them externally, bypassing this problem. The idea is to report on the digital twin the indication of the spaces of which there is a digitization product. In a BIM-GIS environment, a point or surface element will suffice for this operation. These objects can be completed with $\mathrm{n}$. attributes, that describe the available material, including a link that refers to an external web page, on which the material is imported, where the real virtual experience takes place.

To date, frameworks are already available to structure portals with these features. An example is those present on Three.js (Figure 7), a website that directly provides code (using JavaScript programming language) for a navigable display of threedimensional objects. This solution also allows an immersive experience. By accessing these links from the browser of modern VR (virtual reality) viewers it will be possible to experience the spaces in the first person. To test this solution, an Oculus Quest 2 , and the models already uploaded on the Three.js, was used. This solution allows obtaining both an informative system, completed with the connections to its virtual insights, and portals accessible outside the environment, for more tourist use. Indeed, it is recalled that these digital objects are also a functional tool of knowledge for professionals, and not only scenographic products of dissemination.
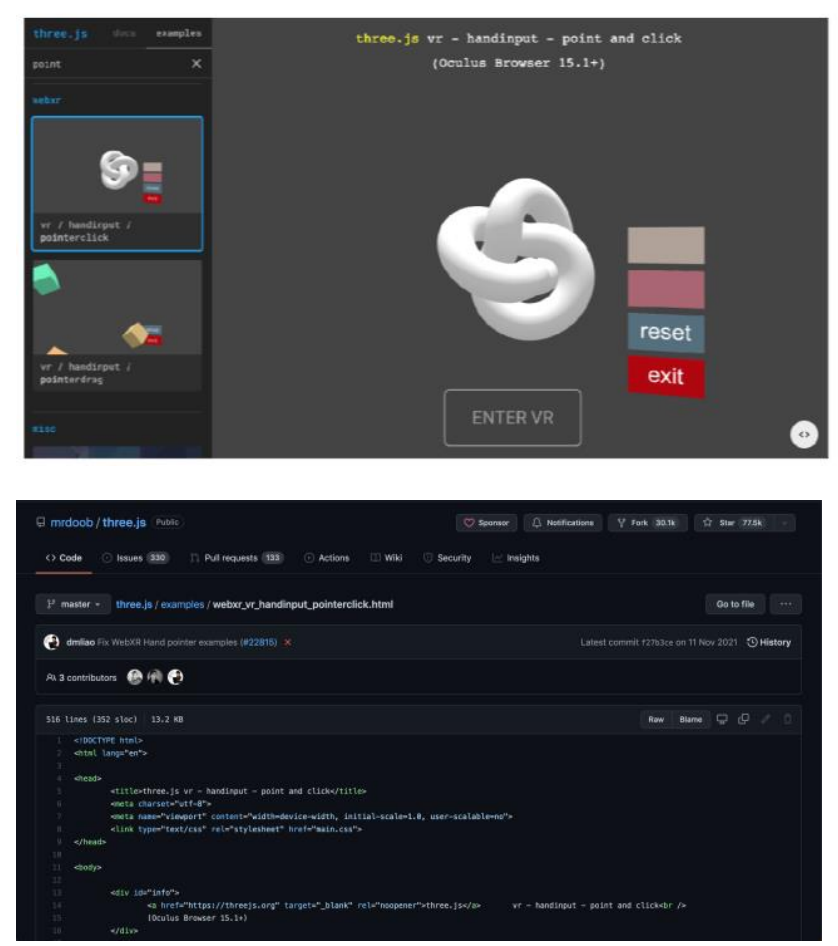

Figure 7. Display of $3 \mathrm{~d}$ objects in Three.js (top) and its available code (bottom)

\subsection{Historical narrative of the $\mathrm{CH}$}

A further theme that has begun to take shape is that concerning the story of the historical-architectural evolution of the $\mathrm{CH}$. We want to emphasize the importance of knowing this information to understand the present conformation and the current processes affecting buildings with a historical character. This theme brings also the possibility of transmitting the knowledge related to the building and, as a consequence, enhancing its conservation.

This approach stems from the observation of the case study. The Castello Sforzesco in Milan is characterized by an articulated history and many important transformations. Past events and their previous forms are rarely part of common knowledge and are preserved only in the mind of a few and in archival documents. Giving an example, in the period of Spanish domination, the Castle occupied an area twice that of the current one. The lost traces of this period do not help the preservation of this memory. In addition, reconstructing these stories is often very difficult due to, for example, the scarcity of documentation or its inconsistency.

More research deal with this issue, structuring different approaches with various techniques and technologies (Banfi and Oreni, 2020; Bolognesi ad Aiello, 2020). The idea we would like to develop consists of an effective and clear way of telling, which exploits cartographic material and 3D representations of the various historical phases. By inserting the graphic elaborations and 3D schematizations in the central system, in the BIM-GIS environment, it is possible to have a comparison between the current conformation and the past ones. All this stems from some particular experience (Iarossi et al., 2014) where this operation is proposed for the whole city of Milan. By preparing for this material also additional external access, as for the virtual experience, it would be possible to bring this knowledge within everyone's reach, giving life to often forgotten stories. 


\section{CONCLUSIONS}

The work exposed represents the attempt to systematize the complexity that characterizes Architectural Cultural Heritage and their transposition into a BIM environment, designed for their needs. This research also aims to be a stimulus to think about the HBIM world differently, placing these buildings again at the centre of the work and the system, and no longer adapting them to the standards designed for new buildings.

The solution stems from the GIS world and its ways of organizing information and reading its relationship.

It cannot be considered a definitive and completely tested model. For this reason, the future objectives concern the more in-depth experimentation of the various levels of information. Special attention will be given to the use of the models in a virtual environment, including the specifications of the materials (extensions, optimal dimensions, etc.). Another important point concerns the precision of the central model, defining its limits and features. Finally, another purpose will be to structure an effective and replicable way to tell the evolution of these complex structures, expanding the above briefly mentioned idea. Understanding the architectonical transformations of $\mathrm{CH}$ throughout history is rarely a simple operation, but also fundamental to understand and operate consciously on them.

\section{ACKNOWLEDGEMENTS}

This research was supported by Soprintendenza Castello, Musei Archeologici e Musei Storici. We thank Prof. Claudio Salsi for this collaboration, Dott. Giovanna Mori for the coordination of the Castle resources and both technical and administrative staff. We thank also R3GIS s.r.l. for the support granted for the project.

\section{REFERENCES}

Agnello, F., Avella, F., Agnello, S., 2019: Vitual reality for historical architecture. Int. Arch. Photogramm. Remote Sens. Spatial Inf. Sci., XLII-2/W9, 9-16. doi.org/10.5194/isprsarchives-XLII-2-W9-9-2019.

Angelidou, M., Angelidou, T., Karachaliou, E., Stylianidis, E., 2017: Cultural heritage in smart city environments. Int. Arch. Photogramm. Remote Sens. Spatial Inf. Sci., XLII-2/W5, 27-32. doi.org/10.5194/isprs-archives-XLII2-W5-27-2017.

Atta, N., Talamo, C., 2019: Digital transformation in facility management (FM). IoT and big data for service innovation. In: Daniotti, B., Gianinetto, M., Della Torre, S. (Eds.), Digital Transformation of the Design, Construction and Management Processes of the Built Environment. Research for Development, Springer, Cham, Switzerland, 267-278. doi.org/10.1007/978-3030-33570-0-24.

Banfi, F., Oreni, D., 2020: Virtual reality (VR), augmented reality (AR), and historic building information modeling (HBIM) for built. Heritage enhancement: from geometric primitives to the storytelling of a complex building. In: Bolognesi, C. et al. (Eds.), Impact of Industry 4.0 on Architecture and Cultural Heritage, IGI Global, Pennsylvania, USA, 48-7. doi:10.4018/978-1-79981234-0.ch005.

Battini, C., Landi, G., 2015: 3D tracking based augmented reality for cultural heritage data management. Int. Arch. Photogramm.
Remote Sens. Spatial Inf. Sci., XL-5/W4, 375-379. doi.org/10.5194/isprsarchives-XL-5-W4-375-2015.

Biagetti, M.T., 2019: Le Biblioteche Digitali. Tipologie, Funzionalità e Modelli di Sviluppo, FrancoAngeli, Milano, Italia. ISBN: 9788891780478.

Bolognesi, C.M., 2018: Digital workflow for virtual and augmented visit of architecture. In: Ioannides, M. et al. (Eds.), Digital Heritage. Progress in Cultural Heritage: Documentation, Preservation, and Protection, Springer, Cham, Switzerland, 126-133. doi.org/10.1007/978-3-030-01765-1_15.

Bolognesi, C.M., Aiello, D., 2020: From digital survey to a virtual tale: virtual reconstruction of the convent of Santa Maria delle Grazie in Milan. In: Bolognesi, C. et al. (Eds.), Impact of Industry 4.0 on Architecture and Cultural Heritage, IGI Global, Pennsylvania, USA, 48-75. doi:10.4018/978-1-7998-12340.ch003.

Brienza, E., Fornaciari, L., 2020: Un sistema integrato per la gestione e la rielaborazione in ambiente tridimensionale della documentazione prodotta dalle indagini archeologiche presso le pendici nord-orientali del Palatino. Archeomatica, 14-20. doi.org/10.48258/arc.v11i1.1711.

Carrion-Ruiz, B., Blanco-Pons, S., Duong, M., Chartrand, J., Li, M., Prochnau, K., Fai, S., Lerma, J.L., 2019: Augmented experience to disseminate cultural heritage: House of Commons windows, Parliament Hill national historic site (Canada). Int. Arch. Photogramm. Remote Sens. Spatial Inf. Sci., XLII-2/W9, 243-247. doi.org/10.5194/isprs-archives-XLII-2- W9-243-2019.

Council of Europe, 2018. European Cultural Heritage Strategy for the 21 st Century. rm.coe.int/european-heritage-strategy-forthe-21st-century-strategy-21-fulltext/16808ae270, (25th March 2021).

Dhanda, A., Reina Ortiz, M., Weigert, A., Paladini, A., Min, A., Gyi, M., Santana Quintero, M., 2019: Recreating cultural heritage environments for VR using photogrammetry. Int. Arch. Photogramm. Remote Sens. Spat. Inf. Sci, XLII-2-W9, 305-310. doi.org/10.5194/isprs-archives-XLII-2-W9-305-2019.

European Commission, 2017, Raccomandazione della Commissione del 27 Ottobre 2011 sulla Digitalizzazione e l'Accessibilità in Rete dei Materiali Culturali e sulla Conservazione Digitale, eurlex.europa.eu/LexUriServ/LexUrServ.do?uri=OJ:L:2011:283 :0039:0045:IT:PDF, (18th December 2020).

Garnero, G., Minucciani, V., 2017: When the culture heritage can not be physically visited. In: Gambardella, C. (Eds.) Heritage and Technology Mind Knowledge Experience, Le Vie dei Mercanti - XIII Forum Internazionale di Studi, Napoli-Capri. La Scuola di Pitagora, Napoli, 508-517. http://hdl.handle.net/2318/1647189.

Gribaudo, M., Iacono, M., Levis, A.H., 2017: An IoT-based monitoring approach for cultural heritage sites: the Matera case. Concurrency and Computation: Practice and Experience, 29(11). doi.org/10.1002/cpe.4153.

Guzzetti, F., Anyabolu, K.L.N., D’A mbrosio, L., Marchetti, G., Sarrecchia, S., 2018: Dal rilievo al modello BIM di una piazza. XXII Conferenza Nazionale ASITA, 27-29 November 2018, Bolzano, Italy, 577-584. 
Guzzetti, F., Anyabolu, K.L.N., Biolo, F., D’Ambrosio, L., 2021: Consideration and questions derived from the application of a scan-to-BIM modeling process of a historical public building, ARQUEOLÓGICA 2.0 \& GEORES 2021, 26-28 April 2021, Valencia, Spain. doi.org/10.4995/Arqueologica9.2021.12093.

Iarossi, M.P., Savini, M., Micalizzi, P., 2014: Ritratti di Città in un Interno. Bononia University Press, Bologna. http://www.ritrattidicitta.it/milano.

Lerario, A., Varesano, A., 2020: An IoT smart infrastructure for S. Domenico church in Matera's "Sassi": a multiscale perspective to built heritage conservation. Sustainability, n12(16). https://doi.org/10.3390/su12166553.

MiBACT, 2021, Piano Triennale per la Digitalizzazione e l'Innovazione dei Musei. musei.beniculturali.it/wpcontent/uploads/2019/08/Piano-Triennale-per-la-

Digitalizzazione-e-1\%E2\%80\%99Innovazione-dei-Musei.pdf, (27th July 2021).

Moretti, M.L., Morezzi, E., Rinaudo, F., Silver, M., Quenda, F., 2016: The CIPA database for saving the heritage of Syria. Int. Arch. Photogramm, Remote Sens. Spatial Inf. Sci., XLI-B5, 953960. doi.org/10.5194/isprs-archives-XLI-B5-953-2016.

Osello, A., Lucibello, G., Morgagni, F., 2018: HBIM and Virtual Tools: A New Chance to Preserve Architectural Heritage. Buildings, 8(1). doi.org/10.3390/buildings8010012.

Padovan, G., 2019: Castrum Portae Jovis Mediolani. Il Castello Visconteo-Sforzesco di Milano dai disegni di Leonardo Da Vinci all'Archeologia del Sottosuolo, BAR Publishing, Oxford, UK. ISBN: 1407356127.

Padovan, G., 1996: La Fortezza Celata. I sotterranei del Castello Sforzesco di Milano, Diakronia Edizioni, Italy.

Partarakis, N., Grammenos, D., Margetis, G., Zidianakis, E., Drossis, G., Leonidis, A., Metaxakis, G., Antona, M., Stephanidis, C., 2017: Digital cultural heritage experience in ambient intelligence. In: Ioannides, M. et al. (Eds.), Mixed Reality and Gamification for Cultural Heritage, Springer International Publishing, Cham, Switzerland, 473-505. doi.org/10.1007/978-3-319-49607-8_19.

Santagati, C., Noto, V., La Russa, F. M., 2018: A project for Museo Civico Castello Ursino in Catania: breaking through museum walls and unlocking collections to everyone. In: Ioannides, M. et al. (Eds.), Digital Heritage. Progress in Cultural Heritage: Documentation, Preservation, and Protection, Springer, Cham, Switzerland, 84-92. doi.org/10.1007/978- 3030-01765-1_10.

Stanga, C., Spinelli, C., Brumana, R., Oreni, D., Valente, R., Banfi, F., 2017: A N-D virtual notebook about the Basilica of S. Ambrogio in Milan: information modeling for the communication of historical phases subtraction process. Int. Arch. Photogramm. Remote Sens. Spatial Inf. Sci., 62W5, 653660. doi:10.5194/isprs-archives-XLII-2-W5-653-2017.

Tommasi, C., Fiorillo, F., Jiménez Fernàndez-Palacios, B., Achille, C., 2019: Access and web sharing of 3D digital socumentation of environmental and architectural heritage. Int. Arch. Photogramm. Remote Sens. Spatial Inf. Sci., XLII-2/W9, 707-714. doi.org/10.5194/isprs-archives-XLII-2-W9-707-2019.
UNESCO, 2020, Charter on the Preservation of Digital Heritage, portal.unesco.org/en/ev.phpURL_ID=17721\&URL_DO=DO_T OPIC\&URL_SECTION=201.html, (1st September 2021).

United Nation, The 17 Sustainable Development Goals_Goal 11, unric.org/en/sdg-11/, (14th September 2021). 